\title{
High-risk clinical stage I nonseminomatous germ cell tumors: the case for chemotherapy
}

\author{
Dirk H. Westermann · Urs E. Studer
}

Received: 21 August 2008 / Accepted: 14 July 2009 / Published online: 28 July 2009

(C) Springer-Verlag 2009

\begin{abstract}
Testis cancer is the most frequent solid malignancy in young men. The majority of patients present with clinical stage I disease and about $50 \%$ of them are nonseminomatous germ cell tumors. In this initial stage of disease there is a subgroup of patients at high risk with a likelihood of more than $50 \%$ for relapse. Treatment options for these patients include: retroperitoneal lymph node dissection (RPLND), albeit 6-10\% of patients will relapse outside the field of RPLND, active surveillance with even higher relapse rates and adjuvant chemotherapy. As most of these patients have the chance to become long-term survivors, avoidance of long-term side effects is of utmost importance. This review provides information on the potential of chemotherapy to achieve a higher chance of cure for patients with high-risk clinical stage I disease than its therapeutic alternatives and addresses toxicity and dose dependency.
\end{abstract}

Keywords Nonseminomatous - Germ cell · Chemotherapy $\cdot$ High risk $\cdot$ Testicular neoplasm

\section{Introduction}

The introduction of cisplatin-based chemotherapy has made testis cancer a highly curable disease. Testis cancer represents the most frequent malignant solid tumor in young

\footnotetext{
D. H. Westermann

Department of Urology,

Staedtisches Klinikum Karlsruhe, Karlsruhe, Germany

U. E. Studer $(\square)$

Department of Urology, University Hospital of Bern, 3010 Bern, Switzerland

e-mail: urology_berne@insel.ch
}

men and $90 \%$ of patients present with clinical stage I disease and normal tumor markers after orchiectomy [1]. Of these, half of patients are diagnosed with nonseminomatous germ cell tumor (NSGCT) of the testis. Treatment options include surveillance with deferred chemotherapy in case of relapse, retroperitoneal lymph node dissection (RPLND) or two courses of bleomycin, etoposide and cisplatin (BEP) chemotherapy, but the preferred management of clinical stage I NSGCT still remains controversial. Although therapeutic approaches differ between countries and institutions, there seems to be no difference in the excellent long-term survival rates of $97 \%$ or more.

Only $30 \%$ of patients have occult metastatic disease found at RPLND, making either routine chemotherapy or RPLND potentially unnecessary therapeutic burdens.

To minimize unnecessary overtreatment, risk stratification for patients at high risk for harboring undetectable metastases were developed in order to administer early adjuvant therapy only to those who most likely need it. Subsequently, a risk-adapted strategy based on the absence or presence of risk factors in the orchiectomy specimen has been recommended as standard procedure [2].

In this review we focus on the role of chemotherapy in patients at high risk to develop metastatic disease and discuss the pros and cons of established alternative treatment options.

\section{Prognostic risk factors}

With the exception of choriocarcinoma and yolk sac tumors that metastasize mainly via hematogenous routes, NSGCTs follow a well known and predictable route of metastatic spread based on the lymphatic drainage of the testes to the retroperitoneal lymph nodes, and efforts have been made to 
identify metastatic lymph nodes in the retroperitoneum. Computed tomography (CT) is only able to distinguish metastatic nodes by size. Newer imaging techniques such as 18-FDG-PET now have additional ability over CT to detect patients at high risk for relapse [3]. As the presence of occult retroperitoneal metastases cannot be reliably ruled out due to inaccuracy of clinical staging methods, multiple studies have been conducted to identify risk factors for pathologic stage II A disease.

In 1987 a multivariate analysis performed by the Medical Research Council (MRC) identified four histopathologic features of the primary tumor that predicted relapse: vascular invasion, lymphatic invasion, absence of yolk sac elements and presence of undifferentiated tumor [4]. On the basis of these features another MRC trial was conducted that showed a recurrence rate of approximately $50 \%$ when three or four of these risk factors were present with vascular invasion (VI) being the most important [5].

In a prospective trial of the German Testicular Study Group, 200 patients were assigned to RPLND [6]. Twentyeight percent of patients were found to have retroperitoneal disease and again VI was the most predictive variable with a positive predictive value (PPV) of $52.7 \%$. This was increased to $63.7 \%$ by adding the MIB score $\geq 70 \%$ and percentage of embryonal carcinoma $(\mathrm{EC})>50 \%$. Patients at low risk for relapse could be identified with a negative predictive value of $86.5 \%$, rendering them good candidates for surveillance.

Moul et al. analyzed 92 patients with clinical stage I NSGCT for histological risk factors. The probability of occult disease rose from $4 \%$ in patients without embryonal components and no VI to $67 \%$ in patients with $50 \% \mathrm{EC}$ and VI, and up to $92 \%$ in patients with pure EC and VI. This gave an almost linear relationship between the percentage of EC and retroperitoneal disease [7]. Other models confirmed the influence of percentage of EC $(\leq 45 \%, 46-79 \%$, $\geq 80 \%$ ) and VI, with odds ratio (OR) of 2.1-7.4 and 8.2-9.0 for the percentage of EC $46-79 \%$ and $\geq 80 \%$, respectively $[8,9]$.

Similar results were published by the Indianapolis group who reported a $46.5 \%$ risk of pathological stage II disease when EC predominance and VI were present in the orchiectomy specimen [10].

Several study groups showed that VI, higher pT-stage (pT2-4 vs. pT1) and EC predominance were most predictive of pathological stage II and the risk of recurrence ranged between 32 and $76 \%$. In a meta-analysis pT-stage and presence of embryonal carcinoma had moderate effects, but MIB-1 staining $>70 \%$ was a promising predictor for relapse (OR 4.7) [11]. Other molecular markers such as p53, bcl-2, cathepsin D and E-cadherin have little predictive value when compared to VI [8].
In summary, several risk factors have been identified; VI and EC are the most powerful predictors for relapse allowing for a risk-adapted treatment. High-risk groups bear a risk of recurrence of approximately 50-60\% and low-risk groups of $13-16 \%$.

\section{Evolution of primary chemotherapy in high-risk clinical stage I NSGCT}

Patients with clinical stage I NSGCT and a high risk of relapse may be cured with chemotherapy. In Europe two courses of BEP are considered the standard treatment option [2]. With this therapeutic approach cure rates of about $98 \%$ are reached.

In 1992 Oliver published the first results of two courses of BEP chemotherapy for patients at intermediate and high risk to develop metastatic disease. Adjuvant chemotherapy was offered when two or more of the high-risk featuresVI, lymphatic invasion, presence of undifferentiated cells, absence of yolk sac tumor elements-were presented. Twenty-one of 22 patients (95.5\%) remained free of metastases. One patient relapsed and died of progressive disease [12].

One year later Studer et al. presented the medium-term results of two courses of adjuvant BEP in a larger series and longer follow-up of patients with clinical stage I NSGCT. In this trial VI, stage $>$ pT1 or the presence of EC were risk factors required for patient eligibility. After a median follow-up of 42 months 40 of 41 patients $(97.6 \%)$ remained relapse free. One patient underwent surgical excision of mature teratoma 26 months after orchiectomy and was disease-free thereafter [13]. These results were updated by Bohlen in 1999 [14].

An Austrian group administered two cycles of BEP polychemotherapy in patients with clinical stage I NSCGT and evidence of VI in the primary tumor [15]. After a median follow-up of 79 months 2 of $29(6.9 \%)$ patients had relapsed and one of them died of progressive disease.

In a multicenter UK Medical Research Council study presented in 1996, 114 eligible patients featuring at least three of the four risk factors (VI, lymphatic invasion, presence of undifferentiated cells, absence of yolk sac tumor elements) received two cycles of BEP [16]. Only two relapses were reported after a follow-up of at least 2 years.

The Spanish Germ Cell Group confirmed these data in a well conducted prospective trial in which 589 patients entered a risk-adapted protocol after orchiectomy. Two hundred and thirty-one patients with the high-risk factors of VI or local infiltration of adjacent structures received two courses of BEP, while patients at low risk for relapse were kept under surveillance. In the chemotherapy group two 
patients $(0.9 \%)$ relapsed, and both are disease-free after salvage therapy [17].

Similar results were published by Klepp, Ondrus, Hendry, Boehlen, Chevreau and Amato with 34, 18, 60, 60, 40 and 76 patients at high risk for occult metastatic disease. Risk factors were slightly different from study to study but included mainly the accepted histologic features known to be predictive for relapse. Recurrences occurred in $0-3 \%$ of cases with excellent long-term survival rates [14, 18-22]. The Medical Research Council piloted a new regimen with two courses of cisplatin, vincristine and bleomycin (BOP) in clinical stage I high-risk patients intending to eliminate the toxicities of etoposide. The 5-year relapse-free rate of 98.3\% in 115 patients was equivalent to that of the BEP regimen, but neurotoxicity was present in $12 \%$ after 2 years and the authors could not show any clear-cut advantages of BOP over the BEP regimen [23].

Hoping to cure patients with a lesser cytotoxic treatment, the Swiss Group for Clinical Cancer Research recently completed a protocol with one single course of BEP chemotherapy for high-risk clinical stage I NSGCT [24]. After a median follow-up of 99 months, 36 of 37 evaluable patients with VI and/or EC predominance ( $>50 \%$ ) remained relapse-free with one possibly treatment-related death with acute respiratory distress syndrome shortly after salvage chemotherapy.

Lately, the German Testicular Cancer Study Group published the results in 382 patients with clinical stage I NSGCT randomized to either RPLND or one cycle of BEP chemotherapy without consideration of risk factors. VI was present in 138 patients (42\%) and was evenly distributed between the two treatment groups. The oncological outcome of this high-risk subpopulation was not determined in the study. The overall difference in the 2-year recurrencefree survival rate between chemotherapy and surgery, however, was $7.04 \%$ in favor of chemotherapy, and the hazard ratio to sustain tumor relapse with RPLND was 7.937 (95\% CI, 1.808-34.48). This is the first randomized trial that proved a superior outcome for one single course of adjuvant chemotherapy over RPLND in clinical stage I NSGCT. Nevertheless, there is a relatively high surgical failure rate after RPLND with seven retroperitoneal and two inguinoscrotal recurrences. Adequacy of RPLND was less than expected in this 61-center trial in which many surgeons performed relatively few procedures. This finding again strongly suggests that RPLND should be performed in specialized high-volume centers only to minimize recurrences.

An overview on the results reported with adjuvant chemotherapy for high-risk clinical stage I NSGCT is presented in Table 1.

\section{Adjuvant chemotherapy in perspective to other treatment modalities}

Since success rates of the established treatment modalities surveillance, RPLND and adjuvant chemotherapy are

Table 1 Chemotherapy for with high-risk clinical stage I NSGCT

\begin{tabular}{|c|c|c|c|c|c|c|}
\hline First author & Year & Chemotherapy & Risk factors & $\begin{array}{l}\text { No. of patients } \\
\text { (evaluable/all) }\end{array}$ & $\begin{array}{l}\text { Relapse } \\
\text { rate }^{\mathrm{a}}\end{array}$ & DOD \\
\hline Oliver [12] & 1992 & $2 \mathrm{BEP}$ & $\geq 2 \mathrm{MRC} R F$ & $22 / 22$ & $1(4.5 \%)$ & $1(4.5 \%)$ \\
\hline Cullen [16] & 1996 & $2 \mathrm{BEP}$ & $\geq 3 \mathrm{MRC} R \mathrm{RF}$ & $109 / 114$ & $2(1.8 \%)$ & $1(0.9 \%)$ \\
\hline Pont [15] & 1996 & $2 \mathrm{BEP}$ & $\mathrm{VI}+$ & $29 / 42$ & $2(6.9 \%)$ & $1(3.4 \%)$ \\
\hline Klepp [20] & 1997 & $3 \mathrm{BEP}$ & $\mathrm{VI}+$ and $\mathrm{AFP}-$ & $32 / 34$ & $1(3 \%)$ & 0 \\
\hline Ondrus [21] & 1998 & $2 \mathrm{BEP}$ & VI+ and/or ECP & $18 / 18$ & 0 & 0 \\
\hline Bohlen [14] & 1999 & $2 \mathrm{BEP}$ or $\mathrm{PVB}$ & $\mathrm{VI}+$ and/or LI+ and/or $\geq \mathrm{pT} 2$ and/or EC+ & $58 / 60$ & $1(1.7 \%)$ & 0 \\
\hline Hendry [22] & 2000 & $2 \mathrm{BEP}$ & $\geq 3 \mathrm{MRC} \mathrm{RF}$ & $60 / 60$ & $1(1.7 \%)$ & $1(1.7 \%)$ \\
\hline Chevreau [19] & 2004 & $2 \mathrm{BEP}$ & $\mathrm{VI}+$ and/or LI+ and/or EC+ & $36 / 40$ & 0 & 0 \\
\hline Amato [18] & 2004 & CEB & 1 or more RF: AFP $>80 \mathrm{ng} / \mathrm{dl},>80 \% \mathrm{EC}, \mathrm{VI}, \mathrm{LI}$ & $68 / 76$ & $1(1.5 \%)$ & 0 \\
\hline Maroto [17] & 2005 & $2 \mathrm{BEP}$ & VI and/or EC+ and/or invasion of local structures & $231 / 231$ & $2(0.9 \%)$ & 0 \\
\hline Dearnaley [23] & 2005 & $2 \mathrm{PVB}$ & VI+ and/or LI+ & $115 / 115$ & $2(1.7 \%)$ & $1(0.9 \%)$ \\
\hline Westermann [24] & 2008 & $1 \mathrm{BEP}$ & $\mathrm{VI}+$ and/or LI+ and/or ECP & $37 / 40$ & $1(2.7 \%)$ & $1(2.7 \%)$ \\
\hline Albers [31] & 2008 & $1 \mathrm{BEP}$ & VI in $41.8 \%$ of patients & $174 / 191$ & $2(1.1 \%)$ & 0 \\
\hline Total & & & & $989 / 1043$ & $16(1.6 \%)$ & $6(0.6 \%)$ \\
\hline
\end{tabular}

$B E P$ bleomycin, etoposide, cisplatin; $B E$ bleomycin, etoposide; $P V B$ bleomycin, vincristine, cisplatin; $C E B$ carboplatin, etoposide, bleomycin; $P V B$ cisplatin, vinblastine, bleomycin; $R F$ risk factor; $D O D$ dead of disease

Risk factors: VI vascular invasion; $L I$ lymphatic invasion; $E C$ embryonal carcinoma; $E C P$ embryonal carcinoma predominance; $M R C$ risk factors vascular invasion, lymphatic invasion, absence of yolk sac tumor, presence of undifferentiated cells; $A F P$ normal pre-orchiectomy AFP serum level

a Contralateral testis cancer excluded 
similar, focus has changed toward minimizing treatmentrelated morbidity by maintaining oncological efficacy.

RPLND is considered the best staging procedure by many US authors and has excellent long-term results and high cure rates, even in case of relapse [10, 25]. Furthermore, it simplifies postoperative follow-up with less frequent abdominal CTs, as recurrence predominantly occurs outside the limits of the surgical templates. Major disadvantages are that about $50 \%$ of all high-risk clinical stage I cancers are overtreated with RPLND and that $8-29 \%$ of patients experience relapse. This is mainly in the mediastinum, even in case of lymph node-negative disease, indicating that metastases bypass the retroperitoneum $[10,26]$. The $29 \%$ rate of distant metastases in high-risk patients with EC predominance and VI in the primary tumor following RPLND, despite histologically negative nodes, is far higher than in the low-risk group, where metastases occur in only $4-6 \%$ of cases $[10,26]$. Therefore, meticulous removal of the retroperitoneal lymph nodes cannot prevent recurrence in all cases and still requires a costly and careful patient follow-up. In addition, as a significant number of patients with clinical stage I-IIA NSGCT and retroperitoneal metastases present with extratemplate disease, an extensive RPLND is a must [27]. Of patients with clinical stage I, but pathological stage IIA disease, $20-40 \%$ will relapse if left untreated after RPLND and will require three to four courses of intensive platinum-based induction chemotherapy $[28,29]$. In such cases cytotoxic morbidity is increased. Thus, the data from the most experienced centers show that RPLND often is not curative when negative or positive nodes have been removed [30], and the rationale for lymph node dissection in the latter patient group is more than questionable. Furthermore, surgical complications occur in $5-14 \%$. Only in experienced hands are postoperative morbidity and ejaculatory dysfunction rates low. In inexperienced hands recurrence and death after RPLND may occur [31].

Active surveillance in clinical stage I NSGCT is the only way to avoid unnecessary over treatment. Non-risk-adapted surveillance protocols have shown relapse rates of $17-38 \%$ due to undetected micrometastases, $17-30 \%$ in the retroperitoneum and about $10 \%$ above to the diaphragm $[4,5,32$, 33]. In patients with high-risk testicular cancer relapse rates rise to $52-75.7 \%$ [32-34], and patients may be under considerable psychological stress due to this. Patients experiencing progressive disease must be exposed to the toxicity of three to four cycles of intensive chemotherapy [22] and despite appropriate salvage therapy, $1-2 \%$ of them die of progressive disease. Therefore, surveillance protocols in patients featuring high-risk factors have been abandoned by several authors. In addition, post-chemotherapy RPLND which may be necessary for residual masses after salvage chemotherapy is associated with higher acute morbidity and reduced preservation of ejaculatory function in $60 \%$ of cases [35].

Most relapses occur within the first 2 years after diagnosis. Therefore, high patient compliance is mandatory not only during this early period of time to detect recurrence at an early stage, but also for many years, as $5-10 \%$ of patients develop late relapse. Frequent abdominal and thoracic $\mathrm{CT}$ or MRI scans are essential for adequate follow-up. In a Canadian multicenter surveillance program the rate of compliance was as low as $64 \%$ for CT scanning during the first 2 years [36]. Compliance was highest in centers with protocols requiring the least frequent visits, but especially surveillance programs require close follow-ups.

An additional disadvantage of repeat CT examinations is the exposure of the patients to a considerable radiation dose. After $10 \mathrm{CT}$ scans, which are usually required for a "wait and watch" policy, an estimated 5 of 1,000 men may develop a radiation-induced secondary malignancy. Considering the current and future $\mathrm{CT}$ use, the estimated risk may rise to $1.5-2.0 \%$ [37]. These data are supported by Chamie et al., who reported on 3,334 patients who chose active surveillance or RPLND for clinical stage I NSGCT. Of these, 172 developed a secondary malignant neoplasm (SMN) after a median follow-up of 16.4 years. Patients under surveillance developed secondary radiation-induced malignancies 1.74 times more frequently than those who underwent RPLND [38]. In addition, also patients without adjuvant therapy face the risk of late toxicity and malignant transformation.

Men with curable testis cancer are long-term survivors. This fact weighs heavily on chemotherapy-related toxicity. Acute and long-term side effects have always strengthened the case against adjuvant chemotherapy and for RPLND, as cisplatin-based cytotoxic treatment is often associated with nephrotoxicity, cardiotoxicity and ototoxicity.

Nephrotoxicity may occur to some degree in patients who receive cisplatin, but it is rare when administered with adequate hydration [14]. Even in patients with disseminated germ cell tumors and poor prognosis treated with high-dose VIP (etoposide, ifosfamide, cisplatin), renal failure is as low as 3\% [39]. Nephropathy is compensated with only serum creatinine elevation and no elevation of other retention parameters.

Concerning cardiotoxicity, no association was found between chemotherapy and an increased risk for cardiovascular disease in clinical stage I or II patients treated with surgery alone or surgery and chemotherapy. In addition, no elevated risk for myocardial infarction (MI) in more than 2,500 5-year survivors of testis cancer was reported for BEP chemotherapy alone, whereas the MI risk after PVB (cisplatin, vinblastine, bleomycin) chemotherapy, mediastinal irradiation and recent smoking was increased 1.9, 3.7 and 2.6-fold, respectively [40]. As for ototoxicity, tinnitus 
and high-tone hearing loss are reported in $20-40 \%$ of patients treated with higher cisplatin doses, but no serious long-term side effects were reported in studies using two BEP cycles for clinical stage I high-risk NSGCT [14-16, 19, 24].

Bleomycin-induced pneumonitis is another rare but well-known problem, especially when smoking is a coexisting risk factor. In testis cancer patients treated with RPLND with or without adjuvant, 3-4 courses of BEP there was no difference in long-term impairment of pulmonary function [41]. To keep pulmonary toxicity as low as possible, in the Swiss BEP protocols bleomycin was given as a 24-h infusion and no lung toxicity was reported [14].

The risk for etoposide induced secondary leukemia is an often cited argument against the use of BEP for NSGCT. Several studies show a risk of $0.5-1 \%$ with cumulative high-dose etoposide doses $>2-8 \mathrm{~g} / \mathrm{m}^{2}$ [42]. Modern BEP regimens remain significantly below this threshold, and no leukemia was reported at doses $<2 \mathrm{~g} / \mathrm{m} 2$, rendering leukemia a negligible concern for NSGCT patients.

The risks of secondary solid malignancies (SMN) in 2,700 5-year survivors of testis cancer were calculated by van den Belt-Dusebout. In NSGCT patients receiving chemotherapy alone, the standardized incidence rate for SMN was 1.4 (0.9-2.1) compared to patients with surgery alone. However, patient data were collected from the period 1965-1995 when treatment protocols with two or less cycles of BEP were not used, and patients were treated with high-dose chemotherapy. Furthermore, the risk of melanoma, which was the predominant SMN followed by bladder cancer, was increased not only after chemotherapy alone, but also after other treatments. This suggested shared genetic origins with NSGCT instead of treatment causality [43].

Furthermore, it is unknown whether the development of a secondary neoplasm is related to an inherent genetic instability which also originated the testicular cancer [44].

Usually, patients with testis cancer are young at the time of diagnosis, and fertility is an important aspect. It is known that $50-70 \%$ of testis cancer patients are subfertile or have impaired spermatogenesis, and even on surveillance alone pregnancy rates are as low as $46 \%$, because gonadal dysfunction is common in these patients. After 3-4 cycles of BEP for advanced disease semen quality normalizes following intermittent depression. When only two courses of chemotherapy are given there is no negative affect on sperm counts after 9-12 months [15, 16].

An important argument against adjuvant chemotherapy is the risk of metastatic adult teratoma to the retroperitoneum, even if absent in the primary tumor. Teratoma is a histologically benign slow growing tumor that is resistant to chemotherapy, and treatment requires complete surgical excision. Metastatic spread is rare $(3 \%)$ in clinical stage I
NSGCT [45], and resection is possible before teratomatous masses cause compression of neighboring structures and before a late relapse with malignant transformation occurs. Another point against adjuvant chemotherapy is the risk of aggressive late relapses in the retroperitoneum. However, these are only related to the initial tumor burden and occur after chemotherapy for bulky metastatic disease at first presentation of patients [46] suggesting incomplete eradication and selection of chemotherapy-resistant cells. Chemoresistant relapse in clinical stage I NSGCT has not been reported so far [47].

Once patients at high risk for relapse are identified, occult metastatic disease can be treated by chemotherapy. The advantage of this strategy is based on the fact that tumor burden is never as small as right after orchiectomy and therefore the quantity of cytotoxic drugs necessary can be reduced to a minimum.

Until now all studies approaching high-risk clinical stage I NSGCT with two courses of chemotherapy such as BEP have been shown to eliminate virtually all occult metastases and to produce excellent survival rates of 98-99\%. Longterm toxicity remains marginal $[15,19,24]$ and poor compliance is negligible, since relapse - in contrast to RPLND or surveillance-is an exception. In addition, double treatment with higher dose salvage chemotherapy after failure of primary RPLND can be avoided.

These are the reasons why the European Consensus Conference on diagnosis and treatment of germ cell cancer suggests two cycles of adjuvant BEP for patients with high-risk clinical stage I as a standard [2]. Studies are underway to elucidate whether even 1 cycle of BEP is sufficient as has been suggested by preliminary data. [24-26]

\section{Conclusion}

Patients with clinical stage I NSGCT at high risk for relapse have an excellent long-term prognosis independent of the therapeutic approach used. Surveillance protocols leave the patients with approximately a $50 \%$ risk for relapse. This exerts a high psychological pressure on patients and extensive chemotherapy in case of relapse if necessary. RPLND alone is not curative if positive nodes are found and leaves the patient with a $6-10 \%$ risk of progression even if the nodes are negative. This implies not only substantial overtreatment for the majority of patients who do not profit from RPLND. Patients may also be exposed to unnecessary morbidity combined with an uncertain cure. In case of extratemplate recurrence high-dose salvage chemotherapy is needed. With the intention to minimize morbidity and maximize efficacy, two courses of adjuvant chemotherapy have turned out to be the best for reaching the goal of cure. Therefore, risk-adapted management with adjuvant 
chemotherapy for high-risk patients with clinical stage I NSGCT seems appropriate. Efforts are being made to further reduce toxicity, and the application of just one single course of BEP may turn out to be the future standard if ongoing trials confirm existing results.

Conflict of interest statement There is no conflict of interest.

\section{References}

1. Sonneveld DJ, Hoekstra HJ, Van Der Graaf WT, Sluiter WJ, Schraffordt Koops H, Sleijfer DT (1999) The changing distribution of stage in nonseminomatous testicular germ cell tumours, from 1977 to 1996 . BJU Int 84(1):68-74

2. Krege S, Beyer J, Souchon R, Albers P, Albrecht W, Algaba F, Bamberg M, Bodrogi I, Bokemeyer C, Cavallin-Stahl E, Classen J, Clemm C, Cohn-Cedermark G, Culine S, Daugaard G, De Mulder PH, De Santis M, de Wit M, de Wit R, Derigs HG, Dieckmann KP, Dieing A, Droz JP, Fenner M, Fizazi K, Flechon A, Fossa SD, Garcia Del Muro X, Gauler T, Geczi L, Gerl A, Germa-Lluch JR, Gillessen S, Hartmann JT, Hartmann M, Heidenreich A, Hoeltl W, Horwich A, Huddart R, Jewett M, Joffe J, Jones WG, Kisbenedek L, Klepp O, Kliesch S, Koehrmann KU, Kollmannsberger C, Kuczyk M, Laguna P, Leiva Galvis O, Loy V, Mason MD, Mead GM, Mueller R, Nichols C, Nicolai N, Oliver T, Ondrus D, Oosterhof GO, Paz Ares L, Pizzocaro G, Pont J, Pottek T, Powles T, Rick O, Rosti G, Salvioni R, Scheiderbauer J, Schmelz HU, Schmidberger H, Schmoll HJ, Schrader M, Sedlmayer F, Skakkebaek NE, Sohaib A, Tjulandin S, Warde P, Weinknecht S, Weissbach L, Wittekind C, Winter E, Wood L, von der Maase H (2008) European consensus conference on diagnosis and treatment of germ cell cancer: a report of the second meeting of the European Germ Cell Cancer Consensus Group (EGCCCG): Part I. Eur Urol 53(3):478-96

3. Huddart RA, O'Doherty MJ, Padhani A, Rustin GJ, Mead GM, Joffe JK, Vasey P, Harland SJ, Logue J, Daugaard G, Hain SF, Kirk SJ, MacKewn JE, Stenning SP (2007) 18fluorodeoxyglucose positron emission tomography in the prediction of relapse in patients with high-risk, clinical stage I nonseminomatous germ cell tumors: preliminary report of MRC Trial TE22-the NCRI Testis Tumour Clinical Study Group. J Clin Oncol 25(21):3090-3095

4. Freedman LS, Parkinson MC, Jones WG, Oliver RT, Peckham MJ, Read G, Newlands ES, Williams CJ (1987) Histopathology in the prediction of relapse of patients with stage I testicular teratoma treated by orchidectomy alone. Lancet 2(8554):294-298

5. Read G, Stenning SP, Cullen MH, Parkinson MC, Horwich A, Kaye SB, Cook PA (1992) Medical Research Council prospective study of surveillance for stage I testicular teratoma. Medical Research Council Testicular Tumors Working Party. J Clin Oncol 10(11):1762-1768

6. Albers P, Siener R, Kliesch S, Weissbach L, Krege S, Sparwasser C, Schulze H, Heidenreich A, de Riese W, Loy V, Bierhoff E, Wittekind C, Fimmers R, Hartmann M (2003) Risk factors for relapse in clinical stage I nonseminomatous testicular germ cell tumors: results of the German Testicular Cancer Study Group Trial. J Clin Oncol 21(8):1505-1512

7. Moul JW, McCarthy WF, Fernandez EB, Sesterhenn IA (1994) Percentage of embryonal carcinoma and of vascular invasion predicts pathological stage in clinical stage I nonseminomatous testicular cancer. Cancer Res 54(2):362-364

8. Heidenreich A, Sesterhenn IA, Mostofi FK, Moul JW (1998) Prognostic risk factors that identify patients with clinical stage I nonseminomatous germ cell tumors at low risk and high risk for metastasis. Cancer 83(5):1002-1011

9. Wishnow KI, Johnson DE, Swanson DA, Tenney DM, Babaian RJ, Dunphy CH, Ayala AG, Ro JY, von Eschenbach AC (1989) Identifying patients with low-risk clinical stage I nonseminomatous testicular tumors who should be treated by surveillance. Urology 34(6):339-343

10. Hermans BP, Sweeney CJ, Foster RS, Einhorn LE, Donohue JP (2000) Risk of systemic metastases in clinical stage I nonseminoma germ cell testis tumor managed by retroperitoneal lymph node dissection. J Urol 163(6):1721-1724

11. Vergouwe Y, Steyerberg EW, Eijkemans MJ, Albers P, Habbema JD (2003) Predictors of occult metastasis in clinical stage I nonseminoma: a systematic review. J Clin Oncol 21(22):4092-4099

12. Oliver RT, Raja MA, Ong J, Gallagher CJ (1992) Pilot study to evaluate impact of a policy of adjuvant chemotherapy for high risk stage 1 malignant teratoma on overall relapse rate of stage 1 cancer patients. J Urol 148(5):1453-1455 (discussion pp 1455-1456)

13. Studer UE, Fey MF, Calderoni A, Kraft R, Mazzucchelli L, Sonntag RW (1993) Adjuvant chemotherapy after orchiectomy in high-risk patients with clinical stage I non-seminomatous testicular cancer. Eur Urol 23(4):444-449

14. Bohlen D, Borner M, Sonntag RW, Fey MF, Studer UE (1999) Long-term results following adjuvant chemotherapy in patients with clinical stage I testicular nonseminomatous malignant germ cell tumors with high risk factors. J Urol 161(4):1148-1152

15. Pont J, Albrecht W, Postner G, Sellner F, Angel K, Holtl W (1996) Adjuvant chemotherapy for high-risk clinical stage I nonseminomatous testicular germ cell cancer: long-term results of a prospective trial. J Clin Oncol 14(2):441-448

16. Cullen MH, Stenning SP, Parkinson MC, Fossa SD, Kaye SB, Horwich AH, Harland SJ, Williams MV, Jakes R (1996) Shortcourse adjuvant chemotherapy in high-risk stage I nonseminomatous germ cell tumors of the testis: a Medical Research Council report. J Clin Oncol 14(4):1106-1113

17. Maroto P, Garcia del Muro X, Aparicio J, Paz-Ares L, Arranz JA, Guma J, Terrassa J, Barnadas J, Dorta J, Germa-Lluch JR (2005) Multicentre risk-adapted management for stage I non-seminomatous germ cell tumours. Ann Oncol 16(12):1915-1920

18. Amato RJ, Ro JY, Ayala AG, Swanson DA (2004) Risk-adapted treatment for patients with clinical stage I nonseminomatous germ cell tumor of the testis. Urology 63(1):144-148 (discussion pp 148-149)

19. Chevreau C, Mazerolles C, Soulie M, Gaspard MH, Mourey L, Bujan L, Plante P, Rischmann P, Bachaud JM, Malavaud B (2004) Long-term efficacy of two cycles of BEP regimen in high-risk stage I nonseminomatous testicular germ cell tumors with embryonal carcinoma and/or vascular invasion. Eur Urol 46(2):209-214 (discussion pp 214-215)

20. Klepp O, Dahl O, Flodgren P, Stierner U, Olsson AM, Oldbring J, Nilsson S, Daehlin L, Tornblom M, Smaland R, Starkhammar H, Abramsson L, Wist E, Raabe N, Edekling T, Cavallin-Stahl E (1997) Risk-adapted treatment of clinical stage 1 non-seminoma testis cancer. Eur J Cancer 33(7):1038-1044

21. Ondrus D, Matoska J, Belan V, Kausitz J, Goncalves F, Hornak M (1998) Prognostic factors in clinical stage I nonseminomatous germ cell testicular tumors: rationale for different risk-adapted treatment. Eur Urol 33(6):562-566

22. Hendry WF, Norman A, Nicholls J, Dearnaley DP, Peckham MJ, Horwich A (2000) Abdominal relapse in stage 1 nonseminomatous germ cell tumours of the testis managed by surveillance or with adjuvant chemotherapy. BJU Int 86(1):89-93

23. Dearnaley DP, Fossa SD, Kaye SB, Cullen MH, Harland SJ, Sokal MP, Graham JD, Roberts JT, Mead GM, Williams MV, Cook PA, Stenning SP (2005) Adjuvant bleomycin, vincristine and cisplatin 
(BOP) for high-risk stage I non-seminomatous germ cell tumours: a prospective trial (MRC TE17). Br J Cancer 92(12):2107-2113

24. Westermann DH, Schefer H, Thalmann GN, Karamitopoulou-Diamantis E, Fey MF, Studer UE (2008) Long-term followup results of 1 cycle of adjuvant bleomycin, etoposide and cisplatin chemotherapy for high risk clinical stage I nonseminomatous germ cell tumors of the testis. J Urol 179(1):163-166

25. Stephenson AJ, Bosl GJ, Motzer RJ, Kattan MW, Stasi J, Bajorin DF, Sheinfeld J (2005) Retroperitoneal lymph node dissection for nonseminomatous germ cell testicular cancer: impact of patient selection factors on outcome. J Clin Oncol 23(12):2781-2788

26. Nicolai N, Miceli R, Artusi R, Piva L, Pizzocaro G, Salvioni R (2004) A simple model for predicting nodal metastasis in patients with clinical stage I nonseminomatous germ cell testicular tumors undergoing retroperitoneal lymph node dissection only. J Urol 171(1):172-176

27. Eggener SE, Carver BS, Sharp DS, Motzer RJ, Bosl GJ, Sheinfeld J (2007) Incidence of disease outside modified retroperitoneal lymph node dissection templates in clinical stage I or IIA nonseminomatous germ cell testicular cancer. J Urol 177(3):937-942 (discussion pp 942-943)

28. Beck SD, Foster RS, Bihrle R, Cheng L, Donohue JP (2005) Does the histology of nodal metastasis predict systemic relapse after retroperitoneal lymph node dissection in pathological stage B1 germ cell tumors? J Urol 174(4 Pt 1):1287-1290 (discussion p 1290)

29. Beck SD, Foster RS, Bihrle R, Cheng L, Ulbright TM, Donohue JP (2005) Impact of the number of positive lymph nodes on disease-free survival in patients with pathological stage B1 nonseminomatous germ cell tumor. J Urol 174(1):143-145

30. Donohue JP, Thornhill JA, Foster RS, Rowland RG, Bihrle R (1993) Retroperitoneal lymphadenectomy for clinical stage A testis cancer (1965-1989): modifications of technique and impact on ejaculation. J Urol 149(2):237-243

31. Albers P, Siener R, Krege S, Schmelz HU, Dieckmann KP, Heidenreich A, Kwasny P, Pechoel M, Lehmann J, Kliesch S, Kohrmann KU, Fimmers R, Weissbach L, Loy V, Wittekind C, Hartmann M (2008) Randomized phase III trial comparing retroperitoneal lymph node dissection with one course of bleomycin and etoposide plus cisplatin chemotherapy in the adjuvant treatment of clinical stage I nonseminomatous testicular germ cell tumors: AUO trial AH 01/94 by the German Testicular Cancer Study Group. J Clin Oncol 26(18):2966-2972

32. Al-Tourah AJ, Murray N, Coppin C, Kollmannsberger C, Man A, Chi KN (2005) Minimizing treatment without compromising cure with primary surveillance for clinical stage I embryonal predominant nonseminomatous testicular cancer: a population based analysis from British Columbia. J Urol 174(6):2209-2213 (discussion p 2213)

33. Roeleveld TA, Horenblas S, Meinhardt W, van de Vijver M, Kooi M, ten Bokkel Huinink WW (2001) Surveillance can be the standard of care for stage I nonseminomatous testicular tumors and even high risk patients. J Urol 166(6):2166-2170

34. Divrik RT, Akdogan B, Ozen H, Zorlu F (2006) Outcomes of surveillance protocol of clinical stage I nonseminomatous germ cell tumors-is shift to risk adapted policy justified? J Urol 176(4 Pt 1):1424-1429 (discussion pp 1429-1430)
35. Sheinfeld J (2002) The role of adjunctive postchemotherapy surgery for nonseminomatous germ-cell tumors: current concepts and controversies. Semin Urol Oncol 20(4):262-271

36. Ernst DS, Brasher P, Venner PM, Czaykowski P, Moore MJ, Reyno L, Winquist E, Segal R, Hao D (2005) Compliance and outcome of patients with stage 1 non-seminomatous germ cell tumors (NSGCT) managed with surveillance programs in seven Canadian centres. Can J Urol 12(2):2575-2580

37. Brenner DJ, Hall EJ (2007) Computed tomography-an increasing source of radiation exposure. N Engl J Med 357(22):22772284

38. Chamie K, Kurzrock E, Romero V, deVerre White RW (2008) Increased risk of secondary malignancy in patients on active surveillance for NSGCT. J Urol 179(4): 172

39. Schmoll HJ, Kollmannsberger C, Metzner B, Hartmann JT, Schleucher N, Schoffski P, Schleicher J, Rick O, Beyer J, Hossfeld D, Kanz L, Berdel WE, Andreesen R, Bokemeyer C (2003) Longterm results of first-line sequential high-dose etoposide, ifosfamide, and cisplatin chemotherapy plus autologous stem cell support for patients with advanced metastatic germ cell cancer: an extended phase I/II study of the German Testicular Cancer Study Group. J Clin Oncol 21(22):4083-4091

40. van den Belt-Dusebout AW, Nuver J, de Wit R, Gietema JA, ten Bokkel Huinink WW, Rodrigus PT, Schimmel EC, Aleman BM, van Leeuwen FE (2006) Long-term risk of cardiovascular disease in 5-year survivors of testicular cancer. J Clin Oncol 24(3):467475

41. Lehne G, Johansen B, Fossa SD (1993) Long-term follow-up of pulmonary function in patients cured from testicular cancer with combination chemotherapy including bleomycin. $\mathrm{Br} \mathrm{J}$ Cancer 68(3):555-558

42. Wierecky J, Kollmannsberger C, Boehlke I, Kuczyk M, Schleicher J, Schleucher N, Metzner B, Kanz L, Hartmann JT, Bokemeyer C (2005) Secondary leukemia after first-line high-dose chemotherapy for patients with advanced germ cell cancer. J Cancer Res Clin Oncol 131(4):255-260

43. van den Belt-Dusebout AW, de Wit R, Gietema JA, Horenblas S, Louwman MW, Ribot JG, Hoekstra HJ, Ouwens GM, Aleman BM, van Leeuwen FE (2007) Treatment-specific risks of second malignancies and cardiovascular disease in 5-year survivors of testicular cancer. J Clin Oncol 25(28):4370-4378

44. Nichols CR, Roth BJ, Heerema N, Griep J, Tricot G (1990) Hematologic neoplasia associated with primary mediastinal germ-cell tumors. N Engl J Med 322(20):1425-1429

45. Sheinfeld J, Motzer RJ, Rabbani F, McKiernan J, Bajorin D, Bosl GJ (2003) Incidence and clinical outcome of patients with teratoma in the retroperitoneum following primary retroperitoneal lymph node dissection for clinical stages I and IIA nonseminomatous germ cell tumors. J Urol 170(4 Pt 1):1159-1162

46. Gerl A, Clemm C, Schmeller N, Hentrich M, Lamerz R, Wilmanns W (1997) Late relapse of germ cell tumors after cisplatin-based chemotherapy. Ann Oncol 8(1):41-47

47. Ronnen EA, Kondagunta GV, Bacik J, Marion S, Bajorin DF, Sheinfeld J, Bosl GJ, Motzer RJ (2005) Incidence of late-relapse germ cell tumor and outcome to salvage chemotherapy. J Clin Oncol 23(28):6999-7004 